\title{
MISE EN SCENE PADA IKLAN REJOICE INDONESIA DENGAN ANALISIS SEMIOTIKA
}

\author{
Surya Darma \\ Program Studi Televisi dan Film, Universitas Potensi Utama \\ E-mail: surya.darma_pu@yahoo.com
}

\begin{abstract}
ABSTRAK
Penelitian ini bertujuan untuk menganalisis mise en scene serta pemaknaan denotasi, konotasi, dan mitos analisis Roland Barthes pada iklan Rejoice Indonesia. Iklan Rejoice Indonesia menampilkan Fatin Shidqia Lubis sebagai brand ambassador pada penayangan iklan melalui media televisi dan channel youtube resmi Rejoice Indonesia. Musik kolaborasi video "Aku \#Hijabisa" merupakan musik kolaborasi video Rejoice dan Fatin. Musik kolaborasi video ini memberi simbol sebagai wanita berhijab jangan takut meraih mimpi dan Rejoice membantu Fatin dan para hijabers untuk meraih mimpinya tanpa masalah rambut. Metode yang digunakan adalah metode kualitatif. Objek Penelitian dan Unit Analisis pada penelitian ini adalah "Mise en Scene pada Iklan Rejoice Indonesia dengan Analisis Semiotika". Sedangkan unit penelitian yaitu analisis keempat unsur Mise en Scene yaitu setting (latar), kostum dan tata rias (make-up), pencahayaan, pemain dan pergerakan. Iklan Rejoice Indonesia dibedah menggunakan teori semiotika Roland Barthes. Makna denotasi yang terlihat yaitu adegan beberapa wanita berhijab sedang menari mengikuti alunan musik dengan gerakan yang sama tanpa takut berkeringat di rambut yang menyebabkan ketombe. Makna konotasi yaitu menjelaskan bahwa seorang wanita berhijab mampu melakukan aktivitas diluar ruangan, hijab tidak menghalangi seorang wanita dalam melakukan beberapa aktivitas seperti bermain basket. Mitos pada Iklan Rejoice Indonesia berkonsep musik kolaborasi memboyong ketidak sengajaan wanita-wanita berhijab yang sedang sibuk dengan aktivitasnya untuk mengikuti lirik lagu dan menari bersama Fatin Shidqia Lubis sebagai brand ambassador. Unsur ketidak sengajaan mengikuti alunan musik dan menari tersebut seperti naluri alami, ditandai dengan kepura-puraan meninggalkan aktivitasnya untuk ikut menari dalam frame tersebut.
\end{abstract}

Kata Kunci : Iklan Rejoice Indonesia,Mise en Scene, Konotasi, Denotasi, Mitos, Semiotika.

\section{ABSTRACT}

This study aims to analyze the mise en scene and the meaning of the Roland Barthes denotation, connotation, and myth analysis in the Indonesian Rejoice advertisement. Rejoice Indonesia advertisements feature Fatin Shidqia Lubis as brand ambassadors for ad serving through television media and Rejoice Indonesia's official youtube channel. "\#Hijabisa" collaboration video is Rejoice and Fatin's video collaboration music. This music collaboration video gives the symbol of being a hijab woman, don't be afraid to achieve your dreams and Rejoice helps Fatin and the hijabers to achieve their dreams without hair problems. The method used is a qualitative method. The object of research and the Analysis Unit in this study is "Mise en Scene in Indonesian Rejoice Advertising with Semiotic Analysis". While the research unit is the analysis of the four elements of Mise en Scene, namely settings (background), costumes and make-up, lighting, performers and movements. The Indonesian Rejoice ad was dissected using Roland Barthes's semiotic theory. The meaning of the denotation seen is the scene of some veiled women dancing to the music with the same movements without fear of sweating in the hair that causes dandruff. The meaning of connotation is to explain that a woman who wears a hijab is able to do outdoor activities, the hijab does not prevent a woman from doing some activities such as playing basketball. Myth in Rejoice Indonesia Ads concept of collaborative music brings unintentional hijab women who are busy with their activities to follow song lyrics and dance with Fatin Shidqia Lubis as brand ambassador. The 
element of inadvertently following the music and dancing is like a natural instinct, marked by the pretense of leaving their activities to participate in dancing in the frame.

Keywords: Indonesian Rejoice Ads, Mise en Scene, Connotation, Denotation, Myth, Semiotics.

\section{PENDAHULUAN}

Iklan Rejoice Indonesia menampilkan Fatin Shidqia Lubis sebagai brand ambassador pada penayangan iklan melalui media televisi dan channel youtube resmi Rejoice Indonesia dengan 559.643 viewers, komentar-komentar positif banyak dilontarkan warga net pada iklan tersebut. Konsep yang dipakai pada iklan Rejoice Indonesia adalah video musik kolaborasi pertama dengan Fatin Shidqia Lubis yang memboyong wanita berhijab dipersembahkan bagi seluruh perempuan pengguna hijab di Indonesia dengan judul Aku \#Hijabisa (Sumber: http//www.youtube.com/watch?v=1ZNshvAdc2k). Fatin Shidqia Lubis dalam channel youtube resminya menjelaskan bahwa musik video terbaru "Aku \#Hijabisa" ini adalah hasil kolaborasi Rejoice dan Fatin. Lagu ini menggambarkan walaupun sebagai hijabers wanita jangan pernah ragu untuk meraih mimpinya dan Rejoice membantu Fatin dan para hijabers untuk meraih mimpinya tanpa masalah rambut. Iklan tersebut mendapat 840.985 viewers dan 269 comments yang dilontarkan oleh warga net (Sumber : $\mathrm{http} / / \mathrm{www}$.youtube.com/watch?v=5S9LfUkdavM).

Iklan adalah media komunikasi antar komunikator dalam suatu sarana penyampaian produk atau jasa ke publik. Tujuan iklan yaitu memberikan informasi dan membujuk para konsumen untuk mencoba atau mengikuti apa yang ada di iklan tersebut, dapat berupa aktifitas mengkonsumsi produk dan jasa yang ditawarkan (Antonius, 2016: 16).

Mise-en-scene adalah segala sesuatu yang tampak di depan kamera dalam sebuah produksi film. Mise-en-scene adalah unsur sinematik yang terdapat diseluruh gambar dalam film (Pratista, 2008: 14-15).

Analisis mise en scene pada iklan Rejoice Indonesia dengan brand ambassador Fatin Shidqia Lubis perlu dianalisis menggunakan semiotika Roland Barthes agar dapat mengetahui tanda dan makna tiap-tiap scene dan mise en scene pada iklan Rejoice Indonesia. Barthes dalam Sobur menjelaskan:

"Semiotika sebagai suatu model dari ilmu pengetahuan sosial memahami dunia sebagai sistem hubungan yang memiliki unit dasar yang disebut "tanda", baik yang dikonstruksikan dengan kata-kata atau simbol yang digunakan dalam konteks sosial" (Sobur: 2003).

Referensi penulisan pustaka yang dirujuk dalam tulisan ini adalah sebagai betikut: Artikel Putra et al, 2015: 104 dengan judul "Representasi Mistik dalam Film Mystics in Bali 1981" menjelaskan bahwa fim Mystics in Bali 1981 menceritakan mistik yang tertuju pada Leak sebagai salah satu bagian mistik di Bali, tetapi disini terlihat adanya dualisme pemahaman mistik. Metode yang digunakan adalah kualitatif dengan pendekatan analisis semiotika sehingga akan didapatkan kesimpulan secara interpretatif. Berdasarkan hasil analisa, penjabaran visual dalam Mise en Scene film Mystics in Bali (1981) adalah memberikan gambaran sebuah Pengeleakan dengan seorang guru yang disebut Balian yang beraliran Pengiwa (Black Magic), dalam ritual Ngelekas ditampilkan beserta Identitas Budaya Bali. Makna dari visual mistik dalam Mise en Scene yang didapat disini adalah Ideologi Budaya Bali (Putra et al, 2015: 164). 
Persamaan peneliti penulis dengan penelitian tersebut yaitu sama-sama menganalisis mise en scene film dengan pengungkapan semiotika Roland Barthes, sedangkan perbedaannya yaitu pada penelitian tersebut merepresentasi visual dari mistik dalam Mise en Scene film Mystics in Bali (1981) memberikan gambaran sebuah Pengeleakan dengan seorang guru yang disebut Balian yang beraliran Pengiwa (Black Magic), dalam ritual Ngelekas yang ditampilkan beserta Identitas Budaya Bali. Penelitian penulis yaitu membahas mise en scene pada iklan rejoice Indonesia dengan analisis semiotika. Sehingga penelitian yang penulis lakukan dengan penelitian tersebut jelas berbeda.

Artikel Malika dan Lestari, 2018 dengan judul "Analisis Semiotika Iklan "Fair and Lovely" Versi Nikah atau S2" pada penelitian ini mengungkapkan mitos perempuan pada iklan Fair and Lovely versi Nikah atau S2. Hasil penelitian ini yaitu makna denotasi Ayah dan Ibu menjodohkan anak perempuannya dengan seorang yang tepat, tetapi anaknya berkeinginan melanjutkan pendidikan S2. Makna konotasi yaitu Ayah dan Ibu nya menginginkan anak perempuannya segera menikah dari pada melanjutkan pendidikan $\mathrm{S} 2$. Mitos iklan Fair and Lovely versi Nikah atau S2 yaitu pada iklan Fair and Lovely versi Nikah atau S2 sangat bertentangan dengan pendidikan dimana perempuan dalam Agama Islam tidak membedakan dengan laki-laki dalam bidang apapun khususnya pendidikan (Malika dan Lestari, 2018).

Persamaan peneliti penulis dengan penelitian tersebut yaitu sama-sama menggunakan kajian semiotika Roland Barthes, sedangkan perbedaannya yaitu pada penelitian tersebut hanya membahas kajian semiotika pada iklan "Fair and Lovely" versi nikah atau S2 sedangkan penelitian penulis memfokuskan analisis mise en scene pada iklan rejoice Indonesia dengan analisis semiotika. Sehingga penelitian yang penulis lakukan dengan penelitian tersebut jelas berbeda.

Hanggarawan, 2015 dalam skripsinya berjudul "Semiotika Mise en Scene dalam Film Pintu Terlarang Karya Joko Anwar". Tujuan dari penelitian ini yaitu mengungkap mise en scene dalam film pintu terlarang, dan mengetahui makna denotasi, konotasi, dan mitos. Pada penelitian ini menggunakan pendekatan kualitatif dengan taraf analisis interpretatif, serta metode analisis semiotik Roland Barthes sebagai pembedahnya. Makna denotasi, mise en scene dalam film pintu terlarang sebagai pembangun emosi penonton dan juga memiliki peran penting sebagai pembentuk estetika film. Pada makna konotasi, mise en scene dalam film Pintu Terlarang memaknai penyampaian garis besar keseluruhan cerita yaitu kedekatan ibu dan anak, sedangkan mitosnya yaitu peneliti mencoba membedah mise en scene dalam film ini merupakan representasi gagasan-gagasan ideologis Joko Anwar sebagai sutradara, diantaranya: stereotipe seniman yang identik dengan gangguan kejiwaan, kritik sarkastik, hingga gagasan tentang penting tidaknya seorang manusia mempunyai anak (Hanggarawan, 2015).

Persamaan peneliti penulis dengan penelitian tersebut yaitu sama-sama menggunakan analisis mise en scene dan kajian semiotika Roland Barthes, sedangkan perbedaannya yaitu pada penelitian tersebut membahas semiotika mise en scene dalam film pintu terlarang karya joko anwar sedangkan penelitian penulis menganalisis mise en scene pada iklan rejoice Indonesia dengan analisis semiotika. Sehingga penelitian yang penulis lakukan dengan penelitian tersebut jelas berbeda.

Demikian yang telah dijelaskan, penulis menganalisis mise en scene pada iklan Rejoice Indonesia dengan analisis semiotika menggunakan model semiotika Roland Barthes sebagai pemecahan masalah yang terdiri dari konotasi, denotasi, dan mitos. 


\section{STUDI LITERATUR}

\subsection{Analisis Mise en Scene}

Mise-en-scene adalah segala sesuatu yang tampak di depan kamera dalam sebuah produksi film. Mise-en-scene adalah unsur sinematik yang terdapat diseluruh gambar dalam film (Pratista, 2008: 14-15). Empat unsur utama Mise-en-scene, yaitu :

a. Setting (Latar)

Cerita tidak terjadi di ruang hampa. Cerita selalu menempati ruang dan waktu tertentu. Tempat dan waktu berlangsungnya cerita dikenal dengan istilah latar atau setting. Fungsi latar adalah membangun kemiripan dengan realitas (Armanto dan Paramita, 2017: 36).

Setting adalah latar beserta propertinya yang tampak pada frame produksi film. Properti yang dimaksud mencakup perabotan, pintu, jendela, kursi, lampu, pohon, dan sebagainya. Setting dalam film dibuat semirip mungkin dengan konteks cerita dalam produksi film. Setting yang dibuat mampu meyakinkan penonton jika film tersebut tampak nyata yang sesuai dengan konteks isi cerita (Pratista, 2017: 98). Setting pada iklan Rejoice Indonesia menggunaka latar arena pergedungan tampak seperti komplek pertokohan, dengan melibatkan wanita sebagai objek utamanya.

\section{b. Kostum dan Tata Rias Wajah (make-up)}

Kostum adalah busana yang gunakan pemain beserta aksesorisnya. Seperti halnya setting, rancangan kostum harus pula otentik sesuai fungsi dan penggunaannya sehingga mampu meyakinkan penonton. Kostum juga dapat menentukan kelas, kelompok, serta status sosial para pelaku cerita. Busana dan aksesorisnya juga mampu memberikan gambaran umum tentang karakter atau kepribadian tokoh cerita (Pratista, 2017: 104). Kostum dengan nuansa hijau dan putih adalah bentuk ciri khas dari Iklan Rejoice Indonesia dengan identitas kemasan produk tersebut (Rejoice).

Tata rias juga memiliki peranan penting dalam pembuatan film, seperti menggambarkan usia, luka atau lebam di wajah, kemiripan dengan seorang tokoh, sosok manusia unik, hingga sosok nonmanusia. Tata rias biasanya digunakan langsung kepada permukaan kulit seorang aktor baik untuk tujuan artistik atau kosmetik. Tata rias yang digunakan pada iklan Rejoice Indonesia terkesan natural dengan menggambarkan karakter perempuan remaja pada umumnya.

\section{c. Pencahayaan}

Seluruh gambar yang ada dalam film, bisa dikatakan merupakan hasil manipulasi cahaya. Cahaya membentuk sebuah benda serta dimensi ruang. Tata cahaya dalam film, yakni kualitas, arah, sumber, serta warna cahaya. Unsur-unsur ini berperan penting dalam membentuk suasana dan mood (Pratista, 2017: 111). Pada iklan Rejoice Indonesia tampak menggunakan cahaya alami sebagai lightingnya, hal yang dilibatkan adalah pencahayaan pagi hati tampak sinar matahari kontras sehinggan tidak berlebihan pada pandangan kamera. Cahaya Key Light: Back Lighting memberikan ketegasan pada tokoh.

Kualitas cahaya mengacu pada intensitas pencahayaan. Cahaya terang (hard light) menghasilkan obyek dengan bayangan yang jelas. Cahaya lembut (soft light) menyebarkan cahaya sehingga terbentuk bayangan yang tipis. Sinar matahari atau cahaya lampu yang menyorot sangat tajam merupakan hard light. Sementara cahaya langit yang cerah merupakan softlight. Hardlight cenderung membuat obyek tampak kontras dengan lingkungannya. Arah cahaya merujuk pada posisi sumber cahaya terhadap obyek yang dituju. Obyek yang dituju biasanya adalah pelaku cerita dan paling sering adalah bagian wajah (Pratista, 2017: 111). 


\section{d. Pemain dan Pergerakannya}

Seorang sineas juga harus mengontrol akting pemain dan pergerakannya. Pelaku cerita memotivasi naratif dan selalu bergerak dalam melakukan sebuah aksi. Pergerakan pelaku cerita selalu dibatasi oleh framing (pembingkaian) pada aspek sinematografi dan tak lepas pula dari pengolahan transisi gambar pada aspek editing. Baik aspek mise-enscene, sinematografi, serta editing memegang peranan penting dalam menjalin kontinuitas sebuah adegan. Pergerakan dan posisi pemain (blocking) dalam sebuah pengadeganan film selalu dibatasi oleh unsur framing. Pembatasan frame ini, tidak lantas membatasi gerak pemain karena melalui sudut pengambilan dan pergerakan kamera, serta teknik editing, pemain dapat bergerak bebas kemana pun, sesuai dengan tuntutan cerita (Pratista, 2017: 116). Tampak pada adegan scene 2 pergerakan 3 wanita dan 1 pria sedang menjalankan akivitas masing-masing dengan penuh kebahagiaan dan gerakan yang lues.

\subsection{Pengertian Iklan}

Iklan merupakan metode dalam penyampaikan ide dan gagasan yang memberikan makna simbolik melalui penayangan visual dalam sebuah iklan. Sesuai dengan karakternya, iklan merupakan bentuk nyata yang tersebar di masyarakat luas sebagai pemahaman terhadap nilai-nilai tertentu (Vera, 2014: 43). Keunikan yang terdapat pada pesan iklan sebagai bentuk kreativitas berupa representasi fenomena yang memberi makna dan kesan kepada penonton atau pembaca iklan (Vera dalam Tenggono dan Sulistyarini, 2016: 394).

Tilman dan Kirkpatrick menjelaskan bahwa iklan merupakan bentuk komunikasi massa yang menawarkan janji kepada konsumen. Pesan yang terdapat pada iklan mampu memengaruhi konsumen untuk memenuhi kebutuhan dalam memperoleh barang dan jasa serta kualitas barang dan jasa. Menurut Wright iklan merupakan media komunikasi massa. Pembedaan iklan dengan teknik komunikasi pemasaran yang lain adalah komunikasi yang non-personal, jadi iklan memakai media dengan menyewa ruang dan waktu. Disamping itu peranan iklan antara lain dirancang untuk memberikan saran pada orang supaya mereka membeli suatu produk tertentu membentuk hasrat memiliknya dengan mengkonsumsinya secara tepat (Sopianah, 2010: 17).

\subsection{Teori Semiotika Roland Barthes}

Roland Barthes dikenal sebagai salah seorang pemikir strukturalis yang getol mempraktikkan model linguistik dan semiologi Saussurean. Ia juga intelektual dan kritikus sastra Prancis yang ternama; eksponen penerapan srukturalisme dan semiotika pada studi sastra. Bertens (2001: 208) menyebutnya sebagai tokoh yang memainkan peranan sentral dalam strukturalisme tahun 1960-an dan 70-an. (Sobur, 2006: 63). Tujuan analisis Barthes ini, menurut Lechte (2001:196), bukan hanya untuk membangun suatu sistem klasifikasi unsur-unsur narasi yang sangat formal, namun lebih banyak untuk menunjukkan bahwa tindakan yang paling masuk akal, rincian yang paling menyakinkan, atau teka-teki yang paling menarik, merupakan produk buatan, dan bukan tiruan dari yang nyata (Sobur, 2006: 69).

Salah satu area penting yang dirambah Barthes dalam studinya tentang tanda adalah peran pembaca (the reader). Konotasi, walaupun merupakan sifat asli tanda, membutuhkan keaktifan pembaca agar dapat berfungsi. Barthes secara panjang lebar mengulas apa yang sering disebut sebagai sistem pemaknaan tataran ke-dua, yang dibangun di atas sistem lain yang telah ada sebelumnya. Sistem kedua ini disebut dengan konotatif, yang didalam 
Mythologies-nya secara tegas ia bedakan dari denotatif atau sistem pemaknaan tataran pertama. Barthes menciptakan peta tentang bagaimana tanda bekerja (Sobur, 2006:69).

Tabel 1. Tabel Peta Tanda Roland Barthes

\begin{tabular}{|c|c|}
\hline 1. Denotative sign (tanda denotatif) & 2. $\begin{array}{r}\text { Signified } \\
\text { (petanda) }\end{array}$ \\
\hline $\begin{array}{l}\text { 3. CONNOTATIVE SIGNIFIER } \\
\text { (PENANDA KONOTATIF) }\end{array}$ & $\begin{array}{l}\text { 4. CONNOTATIVE SIGNIFIED } \\
\text { (PETANDA KONOTATIF) }\end{array}$ \\
\hline
\end{tabular}

(Sumber: Sobur, 2006: 69)

Dari peta tanda Roland Barthes di atas, terlihat bahwa denotatif (3) terdiri atas penanda (1) dan petanda (2). Akan tetapi, pada saat bersamaan tanda denotasi adalah juga penanda konotatif (4). Dengan kata lain, hal tersebut merupakan unsur material: hanya jika anda mengenal tanda "singa", barulah konotasi seperti harga diri, kegarangan, dan keberanian menjadi mungkin (Sobur, 2006: 69)

Jadi, dalam konsep Barthes, tanda konotatif tidak sekedar memiliki makna tambahan namun juga mengandung kedua bagian tanda konotatif yang melandasi keberadaannya. Sesungguhnya, inilah sumbangan Barthes yang sangat berarti bagi penyempurnaan semiologi Saussure, yang berhenti pada penandaan dalam tataran denotatif (Sobur, 2006: 69). Teori Roland Barthes digunakan pada penelitian ini bertujuan untuk menganalisis keempat unsur mise en scene pada iklan Rejoice Indonesia.

\section{PEMBAHASAN}

\subsection{Metode Penelitian}

\section{a. Jenis Penelitian}

Penelitian ini menggunakan metode penelitian kualitatif. Penelitian kualitatif mendefenisikan konsep-konsep yang sangat umum. Penelitian kualitatif dianggap melakukan pengamatan melalui lensa-lensa yang lebar, mencari pola-pola antar hubungan antara konsep-konsep yang sebelumnya tidak ditentukan (Brannen, 2005: 11).

Menurut Lodico, Spaulding, dan Voegtle penelitian kualitatif, yang juga disebut penelitian interpretif atau penelitian lapangan adalah suatu metodologi yang dipinjam dari disiplin ilmu seperti sosiologi dan antropologi dan diadaptasi ke dalam setting pendidikan (Lodico, et al dalam Emzir, 2011: 2). Dalam penelitian kualitatif, pengumpulan data cenderung terdiri atas data dalam bentuk pertanyaan umum untuk memungkinkan partisipan menghasilkan jawaban-jawaban, dan kata-kata (teks) atau data gambar (pictures), informasi dari sejumlah kecil individu atau situs (Emzir, 2011: 6).

\section{b. Objek Penelitian dan Unit Analisis}

Objek Penelitian dan Unit Analisis pada penelitian ini adalah "Mise en Scene Pada Iklan Rejoice Indonesia dengan Analisis Semiotika". Sedangkan unit penelitian yaitu analisis keempat unsur Mise en Scene iklan Rejoice Indonesia dengan pembedahan menggunakan teori semiotika Roland Barthes.

\section{c. Jenis Sumber Data}

Sumber data yang digunakan penulis yaitu: data primer adalah data yang diperoleh dari rekaman video berupa Iklan "Aku \#Hijabisa Rejoice Indonesia" kemudian pengamatan keempat unsur mise en scene dan dipilih potongan visual atau gambar dan 
adegan yang diperlukan untuk penelitian. Selanjutnya data sekunder didapat dari beberapa literatur-literatur yang mendukung data primer seperti internet, dan buku-buku terkait.

\section{d. Teknik Pengumpulan Data}

Teknik pengumpulan data yang digunakan yaitu: Observasi adalah dengan melakukan pengamatan langsung dan bebas terhadap objek penelitian dan unit analisis dengan cara menonton dan mengamati dengan teliti keempat unsur dalam mise en scene, yaitu: setting atau latar, kostum dan tata rias, pencahayaan, pemain dan pergerakannya. Kemudian mencatat, meneliti dan menganalisa sesuai dengan model penelitian yang digunakan. Dokumentasi adalah mencari data mengenai hal-hal yang berkaitan dengan iklan "Aku \#Hijabisa Rejoice Indonesia" melalui internet dan buku-buku yang ada kaitannya dengan penelitian ini.

Data primer dan sekunder terkumpul kemudian diklarifikasikan sesuai dengan pertanyaan penelitian yang telah ditentukan. Setelah data terklarifikasi, dilakukan analisis data keempat unsur mise en scene dengan menggunakan teknik analisis semiotika Roland Barthes.

\subsection{Analisis Kajian}

Objek pembahasan pada iklan Rejoice Indonesia ini adalah beberapa aktivitas wanita berhijab seperti: bermain skateboard, bersepeda, bermain basket, bernyanyi dan memainkan alat musik, menari, mendesain gaun, iklan "Rejoice" ini menekankan bahwa dengan kerudung tidak menghalangi aktivitas wanita muslimah. Scene 1 pada iklan Rejoice Indonesia menunjukkan pada saat Fatin Shidqia Lubis membuka pintu rumah. Terlihat beberapa aktivitas wanita yang menandakan bahwa wanita berhijab mampu berkarya dengan beberapa hal. Berikut merupakan beberapa scene dari iklan Rejoice Indonesia yang menjadi fokus acuan utama penulis.

Tabel 2. Adegan Scene 2 pada 00:05 Detik

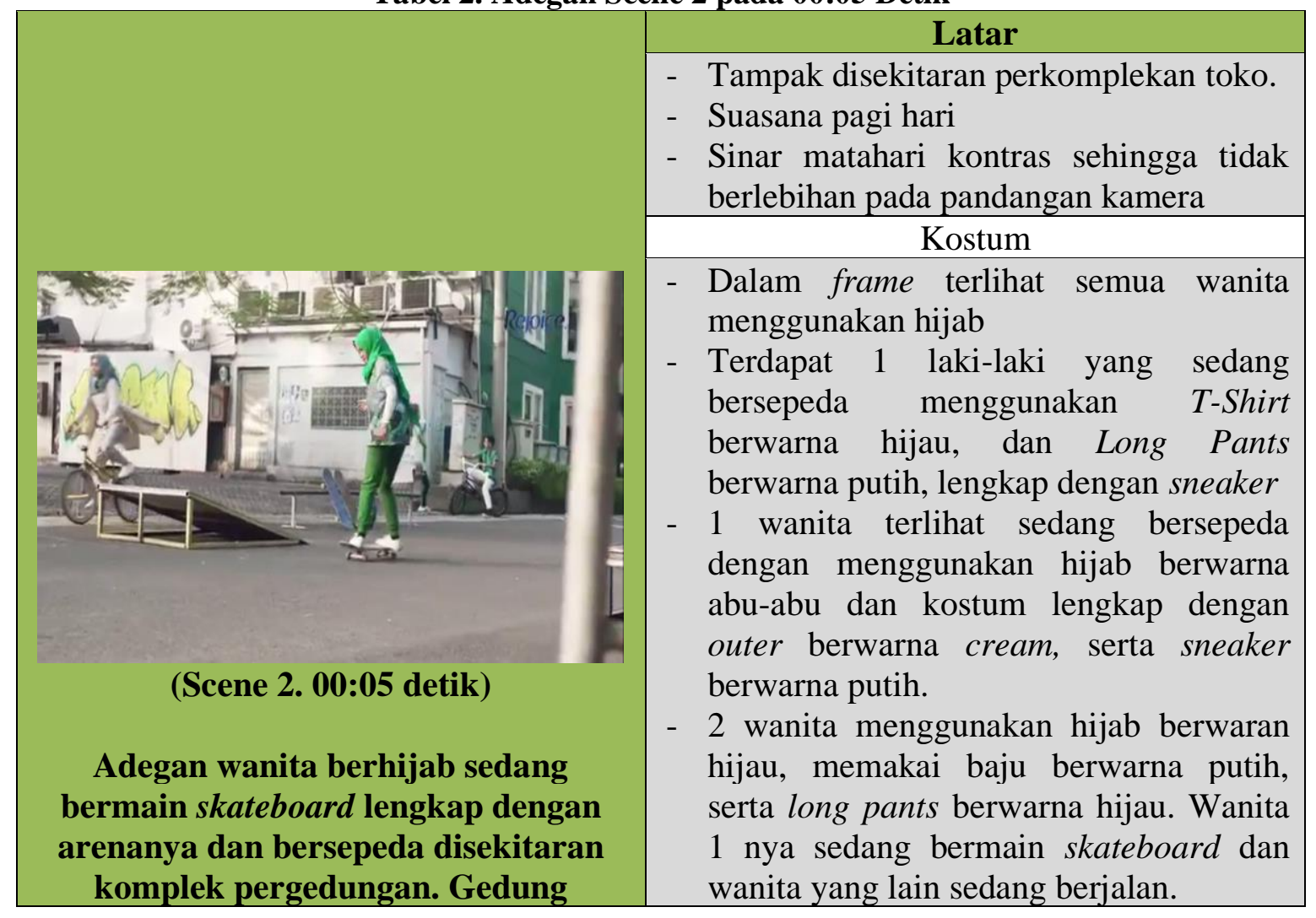




\begin{tabular}{|c|c|}
\hline \multirow{6}{*}{$\begin{array}{l}\text { tersebut terlihat seperti sebuah } \\
\text { komplek pertokoan. }\end{array}$} & Tata Rias Wajah \\
\hline & $\begin{array}{l}\text { Make-up tidak terlalu jelas, hanya terlihat } \\
\text { menggunakan make-up natural. }\end{array}$ \\
\hline & Pencahayaan \\
\hline & $\begin{array}{l}\text { Key Light: Back Lighting berwarna putih. } \\
\text { Pada cahaya ini memberikan ketegasan pada } \\
\text { tokoh. }\end{array}$ \\
\hline & Karakter \\
\hline & $\begin{array}{l}3 \text { wanita dan } 1 \text { pria sedang menjalankan } \\
\text { akivitas masing-masing dengan penuh } \\
\text { kebahagiaan. }\end{array}$ \\
\hline Denotasi & Konotasi \\
\hline $\begin{array}{l}\text { Scene } 2 \text { memperlihatkan adegan } \\
\text { beberapa akivitas wanita berhijab yang } \\
\text { sedang sibuk dengan kegiatannya } \\
\text { masing-masing seperti bersepeda, } \\
\text { bermain skateboard, atau hanya } \\
\text { sekedar berjalan-jalan. Wajah gembira } \\
\text { juga ditampakkan pada diri wanita } \\
\text { tersebut. }\end{array}$ & $\begin{array}{l}\text { Scene } 2 \text { terlihat bahwa sosok wanita } \\
\text { tidak selalu harus diam dirumah karena } \\
\text { banyak aktivitas diluar yang harus } \\
\text { diketahui olehnya. Terlihat pada scene } 2 \\
\text { penggambaran tokoh dalam frame sangat } \\
\text { enerjik disimbolkan dengan aktivitas } \\
\text { wanita pada scene } 2 \text { tersebut seperti } \\
\text { bermain skateboard, bersepeda, atau } \\
\text { sekedar berjalan-jalan. }\end{array}$ \\
\hline \multicolumn{2}{|c|}{ Mitos } \\
\hline \multicolumn{2}{|c|}{$\begin{array}{l}\text { Pada Scene } 2 \text { menggambarkan mitos bahwa perempuan tidak harus berpangku } \\
\text { tangan dirumah, banyak kegiatan positif yang dapat dilakukan oleh kebanyakan } \\
\text { wanita. Scene } 2 \text { juga memberi pesan bahwa aktivitas yang memacu keringat tidak } \\
\text { membuat kulit rambut berketombe. }\end{array}$} \\
\hline
\end{tabular}

Tabel 3. Adegan Scene 3 pada Menit 00:06

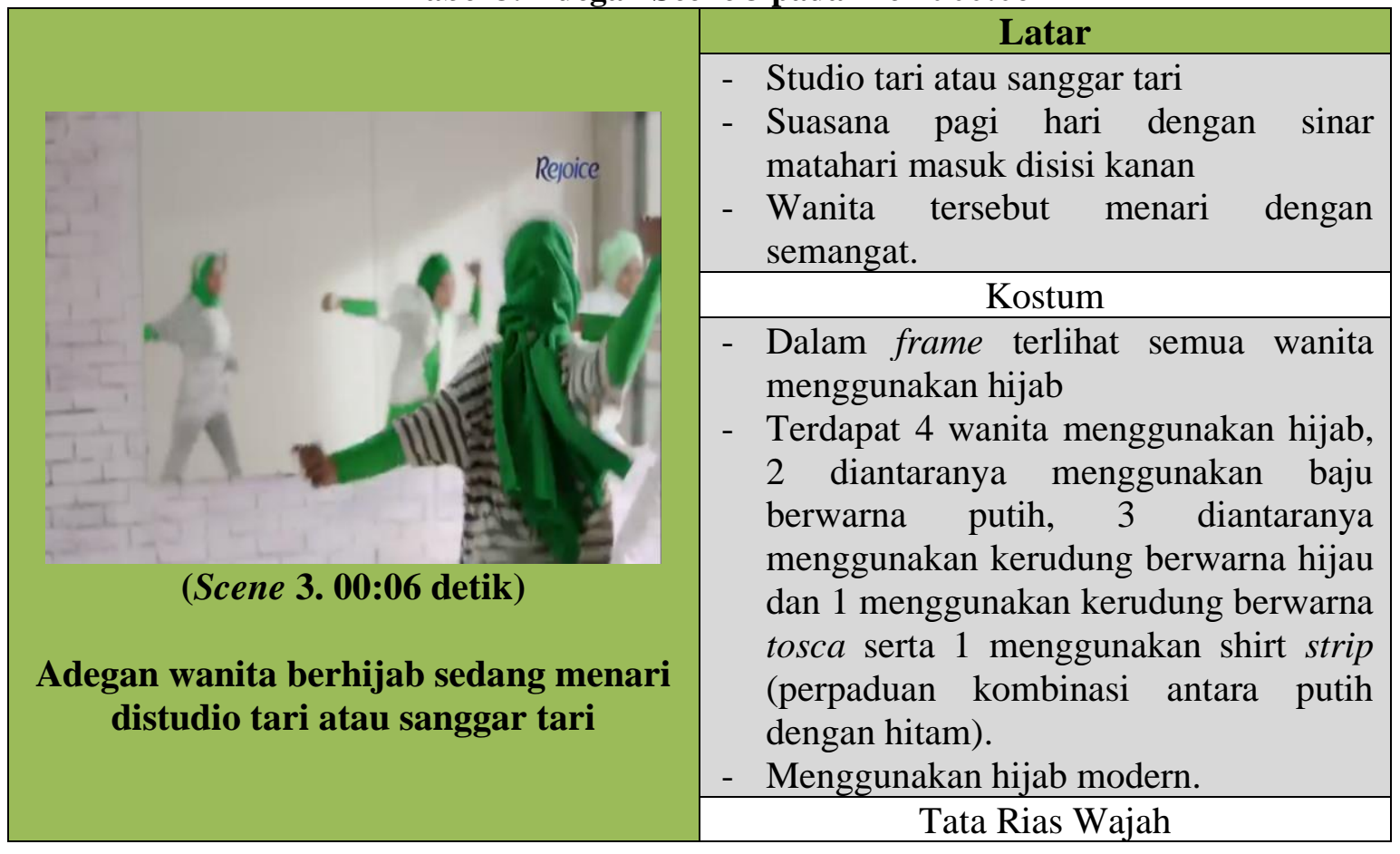




\begin{tabular}{|c|c|}
\hline & $\begin{array}{l}\text { Make-up tidak terlalu jelas, hanya terlihat } \\
\text { menggunakan make-up natural. }\end{array}$ \\
\hline & Pencahayaan \\
\hline & $\begin{array}{l}\text { Key Light: Back Lighting berwarna putih. } \\
\text { Pada cahaya ini memberikan ketegasan } \\
\text { pada tokoh. }\end{array}$ \\
\hline & Karakter \\
\hline & $\begin{array}{l}3 \text { wanita dan } 1 \text { pria sedang menjalankan } \\
\text { akivitas masing-masing dengan penuh } \\
\text { kebahagiaan. }\end{array}$ \\
\hline Denotasi & Konotasi \\
\hline $\begin{array}{l}\text { Scene } 3 \text { beradegan beberapa wanita } \\
\text { sedang menari mengikuti alunan musik } \\
\text { dengan gerakan yang sama antara } \\
\text { wanita yang satu dengan yang } \\
\text { lainnya.Wajah gembira juga } \\
\text { ditampakkan pada diri wanita tersebut. }\end{array}$ & $\begin{array}{l}\text { Scene } 3 \text { memperlihatkan adegan wanita } \\
\text { dapat mengekspresikan dirinya melalui } \\
\text { tarian sebagai bentuk kegembiraan hati } \\
\text { pada dirinya. Menari juga salah satu } \\
\text { jenis hobby wanita yang banyak } \\
\text { digemari. }\end{array}$ \\
\hline \multicolumn{2}{|c|}{ Mitos } \\
\hline \multicolumn{2}{|c|}{$\begin{array}{l}\text { Wajah gembira yang tampak pada diri seseorang tidak selalu mencerminkan rasa } \\
\text { bahagia dihatinya, bisa jadi diri orang tersebut hanya menutupi segala rasa } \\
\text { kekecewaan dihati atau sedang menutupi kesedihan pada diri pribadi orang } \\
\text { tersebut. }\end{array}$} \\
\hline
\end{tabular}

Tabel 4. Adegan Scene 4 pada 00:07 Detik

\begin{tabular}{|c|c|}
\hline \multirow{9}{*}{$\begin{array}{l}\text { (Scene 4. 00:07 detik) } \\
\text { Adegan wanita berhijab sedang bermain } \\
\text { basket, } 1 \text { wanita mendrible bola, } 1 \text { lainnya } \\
\text { merebut bola, } 1 \text { lainnya menghalangi } \\
\text { lawan, dan lawan yang dihalangi } \\
\text { mempersiapkan diri jika temannya } \\
\text { mengoper bola tersebut. }\end{array}$} & Latar \\
\hline & $\begin{array}{ll}\text { - } & \text { Lapangan basket } \\
\text { - } & \text { Suasana pagi hari } \\
\text { - } & \text { Sinar matahari kontras sehingga tidak } \\
& \text { berlebihan pada pandangan kamera }\end{array}$ \\
\hline & $\begin{array}{r}\text { berlebihan pada panda } \\
\text { Kostum }\end{array}$ \\
\hline & $\begin{array}{l}\text { - Dalam frame terlihat semua wanita } \\
\text { menggunakan hijab } \\
\text { - Ke empat wanita tersebut } \\
\text { menggunakan kerudung modern. } \\
\text { - Dua wanita menggunakan baju } \\
\text { berwarna putih, dan } 2 \text { lainnya } \\
\text { menggunakan long pants berwarna } \\
\text { hijau, serta } 2 \text { lainnya menggunakan } \\
\text { baju perpaduan hijau dan putih. }\end{array}$ \\
\hline & \\
\hline & menggunakan make-up \\
\hline & Pencahay \\
\hline & $\begin{array}{l}\text { Back Lighting berwarna putih. } \\
\text { laya ini memberikan ketegasan } \\
\text { h. }\end{array}$ \\
\hline & \\
\hline
\end{tabular}




\begin{tabular}{|l|l|}
\hline & $\begin{array}{l}\text { wanita mendrible bola, 1 lainnya } \\
\text { merebut bola, 1 lainnya menghalangi } \\
\text { lawan, dan lawan yang dihalangi } \\
\text { mempersiapkan diri jika temannya } \\
\text { mengoper bola tersebut. }\end{array}$ \\
\hline \multicolumn{1}{|c|}{ Denotasi } & \multicolumn{1}{|c|}{ Konotasi } \\
\hline $\begin{array}{l}\text { Pada scene } 4 \text { beradegan wanita berhijab } \\
\text { sedang bermain basket, 1 wanita } \\
\text { mendrible bola, 1 lainnya merebut bola, } \\
\text { wanita lainnya menghalangi lawan, dan } \\
\text { lawan yang dihalangi mempersiapkan diri } \\
\text { jika temannya mengoper bola tersebut. }\end{array}$ & $\begin{array}{l}\text { Scene } 4 \text { menjelaskan bahwa seorang } \\
\text { aktivitas diluar ruangan, hijab tidak } \\
\text { menghalangi seorang wanita dalam } \\
\text { bermain basket. }\end{array}$ \\
\hline $\begin{array}{l}\text { Kebanyakan seseorang berfikir bahwa dengan menggunakan hijab membuat } \\
\text { aktivitas sedikit terganggu, pada kenyataannya dengan hijab seorang wanita } \\
\text { terlindungi. Hijab bukan suatu penghalang seorang wanita dalam melakukan segala } \\
\text { aktivitas diluar ruangan. }\end{array}$ \\
\hline
\end{tabular}

Tabel 5. Adegan Scene 4 pada 00:15 Detik

\begin{tabular}{|c|c|}
\hline & Latar \\
\hline & $\begin{array}{ll}\text { - } & \text { Tampak disekitaran perkomplekan } \\
\text { toko. } & \\
\text { - } & \text { Sinar matahari kontras sehingga tidak } \\
\text { berlebihan pada pandangan kamera }\end{array}$ \\
\hline & Kostum \\
\hline (I & $\begin{array}{l}\text { - Dalam frame terlihat semua wanita } \\
\text { menggunakan kerudung kecuali } \\
\text { beberapa wanita yang didalam toko. } \\
\text { - } 2 \text { wanita yang menjadi fokus u } \\
\text { - tama dalam frame menggunakn } \\
\text { kerudung berwarna tosca dengan } \\
\text { manset dan long pants berwarna } \\
\text { putih dengan warna dasar. 1 wanita } \\
\text { sedang bermain gitar menggunakan } \\
\text { shirt berwarna hijau, dan 1 lainnya } \\
\text { menggunakan T-shirt bermotif kotak- } \\
\text { kotak berwaraa dasar hijau. }\end{array}$ \\
\hline (Scene 4. 00:15 detik) & Tata Rias Wajah \\
\hline $\begin{array}{l}\text { Adegan wanita bernyanyi. } 1 \text { wanita } \\
\text { bermain gitar, dan } 1 \text { wanita }\end{array}$ & $\begin{array}{l}\text { Make-up terlihat jelas, menggunakan } \\
\text { make-up natural. }\end{array}$ \\
\hline mendampinginya memainkan "kicrikan". & Pencahayaan \\
\hline $\begin{array}{l}\text { Kedua wanita tersebut tampak gembira, } \\
\text { disimbolkan dengan senyum di wajahnya. }\end{array}$ & $\begin{array}{l}\text { Key Light: Back Lighting berwarna putih. } \\
\text { Pada cahaya ini memberikan ketegasan } \\
\text { pada tokoh. }\end{array}$ \\
\hline & Karakter \\
\hline & $\begin{array}{l}1 \text { wanita bermain gitar, dan } 1 \text { wanita } \\
\text { mendampinginya memainkan "kicrikan". } \\
\text { Kedua wanita tersebut tampak gembira, } \\
\text { disimbolkan dengan senyum di wajahnya. }\end{array}$ \\
\hline
\end{tabular}




\begin{tabular}{|c|c|}
\hline Denotasi & Konotasi \\
\hline $\begin{array}{l}\text { Adegan pada scene } 4 \text { yaitu kolaborasi } \\
\text { antara } 2 \text { wanita berhijab yang sedang } \\
\text { memainkan alat musik dan bernyanyi } \\
\text { bersama. Senyum diwajah kedua wanita } \\
\text { berhijab tersebut tampak jelas dalam } \\
\text { frame yang memberi simbol mereka } \\
\text { sangat enjoy dengan aktivitas tersebut. }\end{array}$ & $\begin{array}{l}\text { Scene } 4 \text { menunjukan bahwa bermain } \\
\text { alat musik khususnya gitar dan } \\
\text { bernyanyi juga salah satu hobi wanita } \\
\text { modern saat ini. }\end{array}$ \\
\hline \multicolumn{2}{|c|}{ Mitos } \\
\hline \multicolumn{2}{|c|}{$\begin{array}{l}\text { Hobi wanita tidak hanya menjahit, menyulam, menenun, shopping ataupun } \\
\text { aktivitas-aktivitas ringan lainnya. Tidak sedikit wanita mulai pandai memainkan } \\
\text { alat musik khususnya gitar, walaupun di Indonesia dominan pria yang dapat } \\
\text { bermain gitar. }\end{array}$} \\
\hline
\end{tabular}

Tabel 6. Adegan Scene 12 pada 00:33 Detik

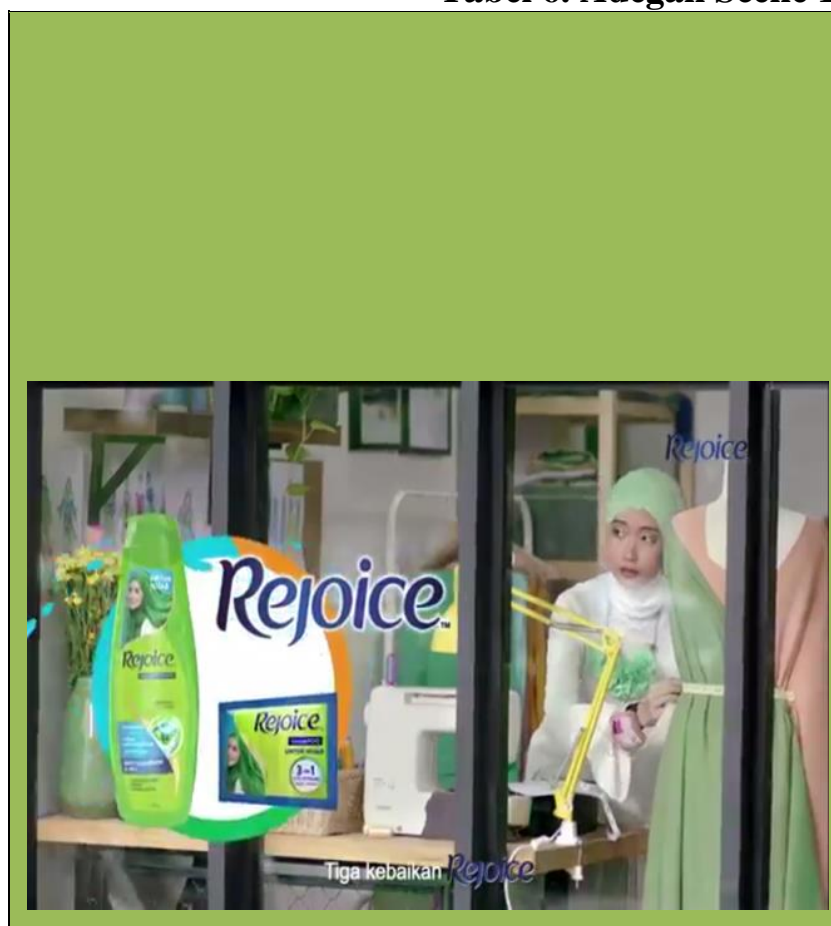

(Scene 12. 00:33 detik) Adegan mendesain dan mengukur gaun.

Didalam toko, Frame tersebut
menggambarkan keadaan suatu toko
seorang desainer disimbolkan dengan
alat penjahit, meteran, maniqueen
lengkap dengan gaun. Ditambah
dengan seorang wanita sedang
melakukan aktivitas mengukur gaun
yang dikenakan maniqueen tersebut.




\begin{abstract}
melihat Fatin Shidqia Lubis sebagai brand ambassador sedang menari dan bernyanyi bersama wanita-wanita hijab yang lainnya. Simbol mata melirik dalam tokoh yang diadegankan pada wanita hijab (desainer) tersebut menunjukkan bahwa wanita tersebut penasaran dengan ativitas diluar kaca tokohnya.
\end{abstract}

\title{
Mitos
}

Mitos yang berkembang pada masyarakat saat ini yaitu hijab tidak selalu merepotkan, bahkan hijab membuat wanita didunia sebagai pelindung.

Tabel 7. Adegan Scene 13 pada 00:41 Detik

\begin{tabular}{|c|c|}
\hline \multirow{9}{*}{$\begin{array}{l}\text { (Scene 13. 00:41 detik) } \\
\text { Adegan wanita berhijab sedang menari } \\
\text { diperkomplekan toko, tampak Fatin } \\
\text { Shidqia Lubis sebagai brand ambassador } \\
\text { Rejoice sebagai dance leader. }\end{array}$} & \begin{tabular}{ll}
\multicolumn{1}{c}{ Latar } \\
- & Tampak disekitaran perkomplekan \\
& toko. \\
- & Suasana pagi hari \\
- & Sinar matahari kontras sehingga tidak \\
& berlebihan pada pandangan kamera
\end{tabular} \\
\hline & Kostum \\
\hline & $\begin{array}{l}\text { - Dalam frame terlihat semua wanita } \\
\text { menggunakan kerudung. } \\
\text { - Fatin Shidqia Lubis sebagai brand } \\
\text { ambassador menggunakan kerudung } \\
\text { berwarna hijau dengan tunik hijau dan } \\
\text { kombinasi warna putih untuk long } \\
\text { pants dan manset. } \\
\text { - Beberapa wanita lainnya yang tampak } \\
\text { pada fokus frame utama menari } \\
\text { sebagai pendamping Fatin Shidqia } \\
\text { Lubis dengan menggunakan kostum } \\
\text { berwarna dasar hijau, dan outer } \\
\text { berwarna putih serta kerudung } \\
\text { berwarna hijau, dan tosca. Secara } \\
\text { umum wanita-wanita dalam frame } \\
\text { menggunakan perapaduan warna putih } \\
\text { dan hijau sebagai simbol dari kemasan } \\
\text { shampoo Rejoice. }\end{array}$ \\
\hline & Tata Rias Wajah \\
\hline & $\begin{array}{l}\text { Make-up terlihat jelas, menggunakan } \\
\text { make-up natural. }\end{array}$ \\
\hline & Pencahayaan \\
\hline & $\begin{array}{l}\text { Key Light: Back Lighting berwarna putih. } \\
\text { Pada cahaya ini memberikan ketegasan } \\
\text { pada tokoh. }\end{array}$ \\
\hline & Karakter \\
\hline & $\begin{array}{l}\text { Wanita-wanita berhijab sedang menari } \\
\text { diperkomplekan toko, tampak Fatin } \\
\text { Shidqia Lubis sebagai brand ambassador } \\
\text { Rejoice sebagai dance leader. }\end{array}$ \\
\hline
\end{tabular}

simbol pada saat seorang wanita mengubah kain utuh dan menjahitnya begitu detail sehingga membantuk gaun yang indah. Hal tersebut juga dilakukan oleh wanita berhijab, sehingga tidak ada alasan untuk tidak menggunakan hijab. 


\begin{tabular}{|c|c|}
\hline & Konotasi \\
\hline $\begin{array}{l}\text { Adegan Scene } 13 \text { yaitu kumpulan wanita- } \\
\text { wanita berhijab sedang menari dengan } \\
\text { kompak, dengan dance leader Fatin Shidqia } \\
\text { Lubis sebagai brand ambassador iklan } \\
\text { Rejoice Indonesia. }\end{array}$ & $\begin{array}{l}\text { Scene } 13 \text { menjelaskan bahwa wanita harus } \\
\text { aktif dalam berkreasi misalnya menari dan } \\
\text { bernyanyi salah satu alternatif unuk } \\
\text { bahagia dalam diri. Wanita-wanita } \\
\text { berhijab harus memotivasi lainnya dalam } \\
\text { berkarya. Potongan lirik pada iklan } \\
\text { Rejoice yaitu "satu rambutku kan lebih } \\
\text { segar, dua lembutnya selalu terasa, tiga } \\
\text { keombe hilang". } \\
\text { Memberi penanda mengajak penonton } \\
\text { untuk menggunakan shampoo Rejoice } \\
\text { khususnya wanita berhijab karena } \\
\text { memberikan } 3 \text { manfaat didalamnya. }\end{array}$ \\
\hline \multicolumn{2}{|c|}{ Mitos } \\
\hline \multicolumn{2}{|c|}{$\begin{array}{l}\text { Iklan Rejoice Indonesia berkonsep musik kolaborasi yang memboyong ketidak sengajaan } \\
\text { wanita-wanita berhijab yang sedang sibuk dengan aktivitasnya untuk mengikuti lirik lagu } \\
\text { dan menari bersama Fatin Shidqia Lubis sebagai brand ambassador. Unsur ketidak } \\
\text { sengajaan mengikuti alunan musik dan menari tersebut seperti naluri alami, ditandai } \\
\text { dengan kepura-puraanya meninggalkan aktivitasnya untuk ikut menari dalam frame } \\
\text { tersebut. Pada Scene } 13 \text { tersebut mengajak penonton untuk berkreasi misalnya menari dan } \\
\text { bernyanyi salah satu alternatif unuk bahagia dalam diri. Wanita-wanita berhijab harus } \\
\text { memotivasi lainnya dalam berkarya. Realitas yang terjadi dimasyarakat tidak sedikit } \\
\text { seorang wanita dalam menemukan kebahagiannya diekspresikan dengan cara shopping, } \\
\text { bertemu kerabat, bertemu keluarga, traveling, dan lain-lain. Hal tersebut menandakan } \\
\text { bahwa kebahagiaan tidak diukur dari satu sisi saja melainkan kebahagaian didapat dalam } \\
\text { hati yang selalu bersyukur. }\end{array}$} \\
\hline
\end{tabular}

\section{KESIMPULAN}

Setelah mendeskripsikan dan menganalisis hasil temuan data analisa visual melalui hasil Mise En Scene pada Iklan Rejoice Indonesia dengan Analisis Semiotika, maka dapat disimpulan sebagai berikut:

1. Iklan Rejoice Indonesia Fatin Shidqia Lubis sebagai brand ambassador merupakan iklan dengan konsep video musik kolaborasi pertama Rejoice dan Fatin.

2. Makna denotasi yang terlihat yaitu adegan beberapa wanita berhijab sedang menari mengikuti alunan musik dengan gerakan yang sama antara wanita berhijab satu dengan yang lainnya. Wajah gembira juga ditampakkan pada diri wanita tersebut.

3. Makna konotasi pada iklan Rejoice Indonesia menjelaskan bahwa seorang wanita berhijab mampu melakukan aktivitas diluar ruangan, hijab tidak menghalangi seorang wanita dalam melakukan beberapa aktivitas seperti bermain basket.

4. Mitos pada Iklan Rejoice Indonesia yang berkonsep musik kolaborasi memboyong ketidak sengajaan wanita-wanita berhijab yang sedang sibuk dengan aktivitasnya untuk mengikuti lirik lagu dan menari bersama Fatin Shidqia Lubis sebagai brand ambassador. Unsur ketidak sengajaan mengikuti alunan musik dan menari tersebut seperti naluri alami, ditandai dengan kepura-puraan meninggalkan aktivitasnya untuk ikut menari dalam frame tersebut. Kebanyakan seseorang berfikir bahwa dengan menggunakan hijab membuat aktivitas sedikit terganggu, pada kenyataannya dengan hijab seorang wanita terlindungi. Hijab bukan suatu penghalang seorang wanita dalam 
melakukan segala aktivitas diluar ruangan. Wanita-wanita berhijab harus memotivasi lainnya dalam berkarya. Realitas yang terjadi dimasyarakat tidak sedikit seorang wanita dalam menemukan kebahagiannya diekspresikan dengan cara shopping, bertemu kerabat, bertemu keluarga, traveling, dan lain-lain. Hal tersebut menandakan bahwa kebahagiaan tidak diukur dari satu sisi saja melainkan kebahagaian didapat dalam hati yang selalu bersyukur.

\section{DAFTAR PUSTAKA}

[1] Armanto, RB. Dan Paramita, Suryana. 2017. Penulisan Skenario Film Panjang. Jakarta : Fakultas Film dan Televisi Institut Kesenian Jakarta.

[2] Brannen, Julia. 2005. Memadu Metode Penelitian Kualitatif dan Kuantitatif. Yogyakarta: Pustaka Pelajar Offset.

[3] Christomy, T. dan Yuwono Untung. 2004. Semiotika Budaya. Depok: Pusat Penelitian Kemasyarakatan dan Budaya Direktorat Riset dan Pengabdian Masyarakat Universitas Indonesia.

[4] Emzir, 2011. Metodologi Penelitian Kualitatif Analisis Data. Jakarta Utara: PT. RajaGrafindo Persada.

[5] Hanggarawan, Ginanjar. 2015. Semiotik Mise en Scene dalam Film Pintu Terlarang Karya Joko Anwar, Tesis Universitas Muhammadiyah Malang.

[6] Malika, Ika dan Lestari, Petri, Sinta. 2018. Analisis Semiotika dalam Iklan "Fair and Lovey versi Nikah atau S2, Jurnal Egaliter, Vol.1 No.2 Maret 2018.

[7] Pratista, Himawan. 2008. Memahami Film. Yogyakarta: Montase Press.

[8] Prianto, Antonius. 2016. Analisis Semiotik Iklan Air Minum dalam Kemasan Aqua Versi “Keluarga Banyu” di Media Televisi, Skriptorium, 2016, Vol. 1, No. 3.

[9] Putra, I Wayan, Daryatma et al 2015. Representasi Mistik dalam Film Mystics In Bali 1981, e-Proceeding of Art and Design, 2015, Vol.2, No.1 April 2015.

[10] Rusmana, Dadan. 2014. Filsafat Semiotika. Bandung: CV. Pustaka Setia.

[11] Sobur, Alex. 2006. Semiotika Komunikasi. Bandung : PT Remaja Rosdakarya Bandung.

[12] Sopianah, Siti. 2010. Analisis Semiotik Terhadap Iklan Susu Bendera Edisi Ramadhan 1430 H di Televisi, Skripsi Universitas Islam Negeri Syarif Hidayatullah Jakarta.

[13] Tenggono, Calvien, Muttaqin. 2016. Analisis Semiotika Pesan Moral dalam Iklan Rokok Sampoerna A Mild "Go Ahead" di Media Televisi, Prosiding Seminar Nasional Komunikasi. Prosiding Seminar Nasional Komunikasi 2016. 


\section{WEBTOGRAFI}

[14] http//www.youtube.com/watch?v=1ZNshvAdc2k : diakses 10 Desember 2018 pukul 09.12 WIB).

[15] http//www.youtube.com/watch?v=5S9LfUkdavM diakses 10 Desember 2018 pukul 10.08 WIB). 